Revista

Ibero-Americana

de Estratégia

\title{
A ESTRUTURA DE CAPITAL COMO RECURSO E O EFEITO NO DESEMPENHO DAS FIRMAS
}

\author{
THE CAPITAL STRUCTURE AS A RESOURCE AND THE EFFECT ON \\ PERFORMANCE OF FIRMS
}

\section{LA ESTRUCTURA DE CAPITAL COMO UN RECURSO Y EL EFECTO EN EL DESEMPEÑO DE LAS EMPRESAS}

\author{
Silvio Parodi Camilo \\ Doutorando em Administração e Turismo na Universidade do Vale do Itajaí - UNIVALI \\ Professor da Faculdade Energia - FASC \\ E-mail: parodi@parodiconsultoria.com.br (Brasil)
}

\section{Wlamir Gonçalves Xavier}

Doutorando em Administração e Turismo na Universidade do Vale do Itajaí - UNIVALI

Pesquisador na Wharton School, Universidade da Pennsylvania - Estados Unidos da América

E-mail: wlamir@uol.com.br (Brasil)

\section{Rodrigo Bandeira-de-Mello}

Doutor em Engenharia de Produção pela Universidade Federal de Santa Catarina - UFSC

Professor da Fundação Getulio Vargas - FGV

E-mail: rodrigo.bandeira.demello@fgv.br (Brasil)

\section{Rosilene Marcon}

Doutor em Engenharia de Produção pela Universidade Federal de Santa Catarina - UFSC

Professor da Universidade do Vale do Itajaí - UNIVALI

E-mail: rmarcon@univali.br (Brasil) 


\title{
A ESTRUTURA DE CAPITAL COMO RECURSO E O EFEITO NO DESEMPENHO DAS FIRMAS
}

\section{RESUMO}

Este trabalho busca contribuir com a linha de estudos sobre a heterogeneidade das firmas, entendendo a estrutura de capital como um importante recurso, unindo Finanças e Estratégia. Pesquisas empíricas sobre resource-based-view (RBV) têm focado nos efeitos de recursos tecnológicos como a capacidade de inovação ou recursos associados à eficiência operacional. Um recurso que merece atenção, em ambientes turbulentos como no Brasil, é a estrutura de capital, pois a combinação das fontes de financiamento é uma formulação importante. Os dados foram coletados de firmas da Bovespa no período de 2002 a 2007. Dois constructos foram analisados, considerando dois indicadores de performance, retorno sobre ativos operacionais e retorno sobre capital próprio. Resultados indicaram que, em relação ao retorno sobre capital próprio, as decisões sobre alavancagem se mostraram relevantes na geração de vantagem competitiva. A pesquisa não se mostrou conclusiva em relação ao retorno sobre os ativos operacionais.

Palavras-chave: Estrutura de Capital; Desempenho; Recurso.

\section{THE CAPITAL STRUCTURE AS A RESOURCE AND THE EFFECT ON PERFORMANCE OF FIRMS}

\begin{abstract}
This article aims to expand the current theoretical and empirical understanding of the capital structure as an important resource to research a firm's performance, from a financial and strategic perspective. Empirical research on resource-based-view (RBV) has either focused on the effects of technological resources and innovative capacity or resources associated with operational efficiency. One feature deserving attention in turbulent environments, such as in Brazil, is the capital structure, as the combination of funding sources is a vital decision. Data was collected from Bovespa listed firms between 2002 and 2007. Two performance constructs were suggested and assessed; firm performance was measured through return on operational assets (ROA) and return on equity (ROE). Results provide empirical evidence that decisions concerning financial leverage (DFL) are relevant to enhance competitive advantage. This study was inconclusive regarding the capital structure's influence on the ROA.
\end{abstract}

Keywords: Capital Structure; Performance; Resource.

Revista Ibero-Americana de Estratégia - RIAE, São Paulo, v. 9, n. 1, p. 102-126, jan./abr. 2010. 
Silvio Parodi Camilo, Wlamir Gonçalves Xavier, Rodrigo Bandeira-de-Mello \& Rosilene Marcon

\section{LA ESTRUCTURA DE CAPITAL COMO UN RECURSO Y EL EFECTO EN EL DESEMPEÑO DE LAS EMPRESAS}

\section{RESUMEN}

Este trabajo busca contribuir con la línea de estudios sobre la heterogeneidad de las empresas, considerando la estructura de capital como un importante recurso, uniendo Finanzas y Estrategia. Las investigaciones empíricas sobre resource-based-view (RBV) han enfocado en los efectos de los recursos tecnológicos como la capacidad de innovación o los recursos asociados a la eficiencia operacional. Es la estructura de capital, es un recurso que merece atención, en ambientes turbulentos como en Brasil, pues la combinación de las fuentes de financiamiento es una formulación importante. Los datos fueron recolectados de empresas de la Bovespa en el período del 2002 al 2007. Dos constructos fueron analizados, considerando dos indicadores de performance, retorno sobre los activos operacionales y retorno sobre el capital propio. Los resultados indicaron que, con relación al retorno sobre el capital propio, las decisiones sobre el apalancamiento se mostraron relevantes en la generación de la ventaja competitiva. La investigación no se mostró conclusiva con relación al retorno sobre los activos operacionales.

Palabras-clave: Estructura de Capital; Desempeño; Recurso.

Revista Ibero-Americana de Estratégia - RIAE, São Paulo, v. 9, n. 1, p. 102-126, jan./abr. 2010. 
A Estrutura de Capital como Recurso e o Efeito no Desempenho das Firmas

\section{INTRODUÇÃO}

O trabalho seminal de Penrose (1959) trouxe importante perspectiva à firma ao explicar como recursos influenciam o seu tamanho. Vista como uma organização em crescimento, sua complexidade e diversidade passaram a ser estudadas sob outras formas de abordagens, tais como: sociológica, organizacional, engenharia ou economia. $\mathrm{O}$ desempenho distintivo entre as organizações demonstra que as firmas são heterogêneas em termos de recursos e capacidades (Barney, 1991; Rumelt, 1991).

Investigar como e porque as organizações são diferentes (Richard, 1991) e como obtém vantagem competitiva contínua, tornou-se um interesse permanente de pesquisadores que se dedicam ao estudo da administração estratégica. A Resource-Based View (RBV), combinando a análise interna da empresa e externa do setor e da arena de competição, procura explicar como os recursos da firma impulsionam seu desempenho, num ambiente competitivo e dinâmico (Collins \& Montgomery, 2000). A RBV, inspirada nos estudos de Penrose (1959), Wernerfelt (1984) e difundidas por Barney (1991) e Peteraf (1993), vem ganhando proeminência na literatura de administração estratégica (Acedo, Barroso, \& Galan, 2006).

A RBV pressupõe que as firmas são diferentes, pois são compostas por recursos e capacidades distintivos. Como sintetizado por Barney (1991), um recurso para ser fonte de vantagem competitiva sustentável deve ser raro, valioso e de difícil imitação e substituição. Com base nisso, a pesquisa empírica sobre RBV tem-se dedicado em examinar a relação de diferentes recursos e capacidades com a performance das firmas. Dentre os principais tipos de recursos estão: os tecnológicos; a capacidade de inovação e recursos necessários à eficiência operacional, tais como: recursos humanos e logísticos.

Contudo, para o ambiente do Brasil outros tipos de recursos parecem importantes e são pouco explorados pelas pesquisas internacionais e nacionais. Argumenta-se, aqui, que recursos associados à forma com que a firma lida com a instabilidade de mercados assume importância central. Para suprir essa lacuna sobre a vantagem competitiva de empresas que operam no Brasil, neste artigo, examinam-se os efeitos das decisões sobre a estrutura de capital na criação de vantagens competitivas. Mostra-se que tais decisões podem formar um recurso organizacional que é raro, valioso e de difícil imitação e substituição, e importante para a vantagem competitiva em um ambiente como o do Brasil. Assim, este artigo parte da suposição de que as firmas que melhor gerenciam o grau de liberdade em termos de alavancagem têm melhor performance. Fazer uso dessa capacidade nas decisões de estrutura de capital é um recurso importante, sendo um dos fatores que contribuem para a heterogeneidade no desempenho.

Revista Ibero-Americana de Estratégia - RIAE, São Paulo, v. 9, n. 1, p. 102-126, jan./abr. 2010. 
Silvio Parodi Camilo, Wlamir Gonçalves Xavier, Rodrigo Bandeira-de-Mello \& Rosilene Marcon

Booth, Aivazian, Demirguc-Kunt e Maksimovic (2001) ao analisarem a estrutura de capitais das firmas dos países em desenvolvimento, dentre os quais o Brasil, apontaram a necessidade de se fazer pesquisas empíricas com modelos teóricos que relacionem desempenho e escolhas de estrutura de capital.

Dessa forma, este artigo pretende contribuir com a análise de determinantes que auxiliem a explicar a dessemelhança no desempenho das firmas, investigando como são as escolhas das estruturas de capital e qual a relação dessas com a performance. Unem-se dois campos de conhecimento, Finanças e Estratégia, para melhor explicar as fontes de vantagem competitiva das firmas no Brasil.

\section{VISÃO BASEADA EM RECURSOS}

\subsection{ORIGEM E PRESSUPOSTOS DA RBV}

O inconformismo em relação aos métodos da microeconomia neoclássica proporcionou o florescimento de novos interesses na dinâmica dos setores industriais (Kupfer \& Hasenclever, 2002). Preocupações sobre a natureza e o funcionamento das firmas e influências do mercado foram explicadas por duas correntes do pensamento econômico. A corrente principal (mainstream), nomeadamente Organização Industrial (OI) ou Economia Industrial (EI), com foco mais tradicional, foi estruturada a partir dos trabalhos de Edward Mason e Joe S. Bain, assim, desenvolvendo o modelo denominado Structure-Conduct-Performance (SCP) (Conner, 1991; McWillians \& Smart, 1993; Vasconcelos \& Cyrino, 2000). Nesta concepção, segundo os autores, a performance é dependente do comportamento das firmas no setor e esse, por sua vez, é influenciado pela estrutura de mercado. A corrente alternativa liderada pelo pensamento de Joseph Schumpeter, neoschumpeteriana, propôs o desenvolvimento de teorias centradas na acumulação de capacidades, na dinâmica da criação de riqueza das empresas e dos setores industriais, desconsiderando a premissa de equilíbrio e maximização de lucros (Kupfer \& Hasenclever, 2002).

O modelo da SCP adotou uma visão focada na conduta estratégica dos participantes de uma mesma indústria. No início da década de 80, Michael Porter, empreendendo nova concepção ao campo da administração estratégica, com base no modelo de Mason e Bain, propôs enfoque diferenciado ao conceito disseminado pela OI, atribuindo importância à estrutura industrial (Peng, 2008). Por meio do "modelo das cinco forças" (Porter, 1986), explicou que as forças externas à

Revista Ibero-Americana de Estratégia - RIAE, São Paulo, v. 9, n. 1, p. 102-126, jan./abr. 2010. 
A Estrutura de Capital como Recurso e o Efeito no Desempenho das Firmas

indústria afetam todas as empresas daquele contexto, que agem para se defender dessa pressão. As ações exercidas pelas forças competitivas e a ação das firmas determinam a lucratividade da indústria, pois influenciam preços, custos e investimentos, fatores básicos para a rentabilidade.

As diferentes habilidades das empresas para identificar as fontes e lidar com esse conjunto de forças é que são determinantes à obtenção de rentabilidade acima da dos competidores (supranormal). Barney (1991) entende que a proposta de Michael Porter descreve os atributos de uma indústria atrativa e sugere que as oportunidades sejam maiores e as ameaças menores, nesse tipo de indústria. Em adição, sugere que as firmas deveriam analisar o ambiente competitivo, feito isso, fazer escolhas estratégicas e adquirir os recursos necessários para implementar as estratégias.

$\mathrm{Na}$ visão porteriana, a heterogeneidade dos recursos é considerada efêmera no âmbito da firma na indústria ou da firma no grupo estratégico. Os recursos são considerados como sendo livremente móveis entre as firmas, ou seja, o fato de as firmas serem ou não diferentes quanto aos seus recursos não influencia a vantagem competitiva (Barney, 1991). Ao contrário do foco no ambiente externo, a RBV define a firma como um conjunto ou feixe de recursos e focaliza-se no seu ambiente interno, nos seus recursos e capacidades (Barney, 2001). Diferentemente das posições da OI e de Porter, a RBV entende que a origem da vantagem competitiva está em determinados recursos e capacidades desenvolvidos pelas firmas, importantes para aproveitar oportunidades e se defender de ameaças. A RBV assenta seus pressupostos centrais na heterogeneidade da firma salvo as variações de tamanho (Dierickx \& Cool, 1989) - e na imobilidade de recursos da empresa (Peteraf, 1993; Mahoney, 2004).

\subsection{FUNDAMENTOS DA RBV}

Visando esclarecer a perspectiva da RBV, Barney (1991) apresentou três conceitos da firma, a saber: a) recursos da firma; b) vantagem competitiva; c) vantagem competitiva sustentável. Os recursos da firma são "todos os ativos, capacidades, processos organizacionais, atributos da firma, informações, conhecimentos etc.”. Em razão de numerosos recursos possíveis, categorizou os recursos em três modalidades: a1) de capital físico; a2) de capital humano; e a3) de capital organizacional. Nos recursos de capital físico considera a tecnologia interna de uso na firma, a planta e equipamentos, a localização geográfica, e o acesso à matéria-prima. Como capital humano inclui o treinamento, experiência, discernimento, inteligência, relacionamentos e percepções individuais dos gestores e trabalhadores na firma. Os recursos de capital organizacional abrangem a estrutura formal, planejamento formal e informal, sistemas de coordenação e controle, relações

Revista Ibero-Americana de Estratégia - RIAE, São Paulo, v. 9, n. 1, p. 102-126, jan./abr. 2010. 
Silvio Parodi Camilo, Wlamir Gonçalves Xavier, Rodrigo Bandeira-de-Mello \& Rosilene Marcon

informais entre grupos dentro da firma e entre aquelas firmas de seu ambiente. No segundo conceito, a firma adquire posição de vantagem competitiva quando suas estratégias de criação de valor são capazes de gerar rendas consistentemente superiores aos demais competidores. No último, a vantagem competitiva sustentável somente ocorre quando a firma consegue manter performance superior no longo do tempo.

Barney (1991) afirma que a implementação simultânea da mesma estratégia de valor, por competidores, neutraliza a obtenção de vantagem competitiva. Todavia, considera que o tempo não é um fator importante, já que a vantagem competitiva sustentável importa em algo mais duradouro, que é inibida, não em função do tempo para se tornar homogênea, mas pela inabilidade ou incapacidade dos competidores. Segundo Conner (1991), na abordagem da RBV, a administração estratégica centra-se sobre os atributos da firma, como fonte de rendas, que são custosos para copiar, como exemplo nos sistemas de produção e distribuição. Com esta perspectiva, a habilidade de uma empresa em alcançar e manter sua posição num mercado rentável depende de sua habilidade de ganhar e defender posições vantajosas, sustentada por importantes recursos subjacentes.

Um melhor "feixe de recursos" protege a firma na manutenção de posição privilegiada, seja no âmbito de produto no mercado (Dierickx \& Cool, 1989) ou na geração de maior atratividade de interessados aquisição de tais recursos (Wernerfelt, 1984). Todavia, Penrose ( citado por Kor e Mahoney, 2004) destaca a importância da gestão inovadora e eficaz dos recursos, visando torná-los produtivos. A simples posse ou disposição de recursos não assegura vantagem competitiva à firma. Acrescenta que a criação de valor econômico está associada ao gerenciamento idiossincrático de um feixe de recursos, a produtividade superior dos recursos depende do emprego de habilidades em que as estratégias são implementadas, com base na superioridade dos recursos (Peteraf, 1993).

De acordo com essa perspectiva, os recursos essenciais, aqueles geradores de vantagem competitiva sustentável, estão alicerçados em quatro atributos nucleares da RBV (Barney, 1991): a) devem ser valiosos, pois somente recursos que agregam valor geram vantagens competitivas, seja explorando oportunidades ou neutralizando entrantes; b) devem ser raros, incomuns entre os competidores correntes e potenciais; c) devem ser de imitação imperfeita, onde os competidores teriam dificuldade para imitá-lo. Os recursos podem ser imperfeitamente imitáveis - barreiras à imitação (Peteraf, 1993) - por uma combinação de três fatores: quando a habilidade da firma para obter o recurso é dependente da sua condição histórica, do caminho percorrido através da acumulação de experiência - dependência da trajetória (path dependency) - sugerindo a interdependência de eventos desenvolvidos ao longo do tempo; quando a ligação entre a posse dos recursos pela firma e a vantagem competitiva sustentável tem causalidade ambígua (causally

Revista Ibero-Americana de Estratégia - RIAE, São Paulo, v. 9, n. 1, p. 102-126, jan./abr. 2010. 
ambiguous), sendo de difícil identificação. Uma razão final para que os recursos possam ser imperfeitamente imitáveis é que eles podem ser fenômenos sociais muito complexos (social complexity), resultantes de relações pessoais internas e externas da firma; d) devem ser insubstituíveis, ou de difícil substituição estratégica equivalente, para os recursos que são valiosos, mas não são nem raros nem de imitação imperfeita.

Peteraf (1993) adicionou contribuição ao modelo da RBV, propondo determinadas condições para a sustentação da vantagem competitiva. Em síntese, com o objetivo de ilustrar as visões da perspectiva de RBV, a Figura 1, a seguir, foi elaborada de acordo com os autores Barney (1991, 2001) e Peteraf (1993), a saber: a) a heterogeneidade pressupõe a existência de diferenças intrínsecas nos fatores produtivos. Em termos eficiência, alguns são superiores em relação a outros, proporcionando custos médios mais baixos e rendas mais elevadas (ver rendas ricardianas), embora se torne mais atratividade aos competidores. Segundo Peteraf (1993), esta variação de capacidades das firmas contribui para um menor equilíbrio do mercado competitivo; b) a mobilidade imperfeita considera que os recursos não podem ser transacionáveis. Por serem idiossincráticos, os recursos têm mais valor dentro do que fora da firma, sua reprodução é altamente incerta. Pois, outra empresa não obteria os mesmos rendimentos; c) a limitação ex-post considera que os recursos obtidos pela empresa sejam de difícil ou de impossível imitação, preservando a natureza das rendas geradoras de vantagem competitiva sustentável. A condição de heterogeneidade precisa ser preservada através de fatores que possibilitem a duração desta condição, por mecanismos de isolamento; d) a limitação $e x$ ante considera que os recursos devem ser adquiridos com ausência dos competidores.

A posse de recursos superiores não deve despertar interesse aos demais competidores. A informação sobre determinada oportunidade para empreender uma estratégia, antes dos competidores, é fundamental para a manutenção da posição de vantagem. Por isso, as firmas, por meio de gerenciamentos distintivos da estrutura de capital, podem fazer uso dessa capacidade para a obtenção de vantagem competitiva.

Revista Ibero-Americana de Estratégia - RIAE, São Paulo, v. 9, n. 1, p. 102-126, jan./abr. 2010. 
Silvio Parodi Camilo, Wlamir Gonçalves Xavier, Rodrigo Bandeira-de-Mello \& Rosilene Marcon

Figura 1 - O framework das condições para a obtenção da vantagem competitiva sustentável.

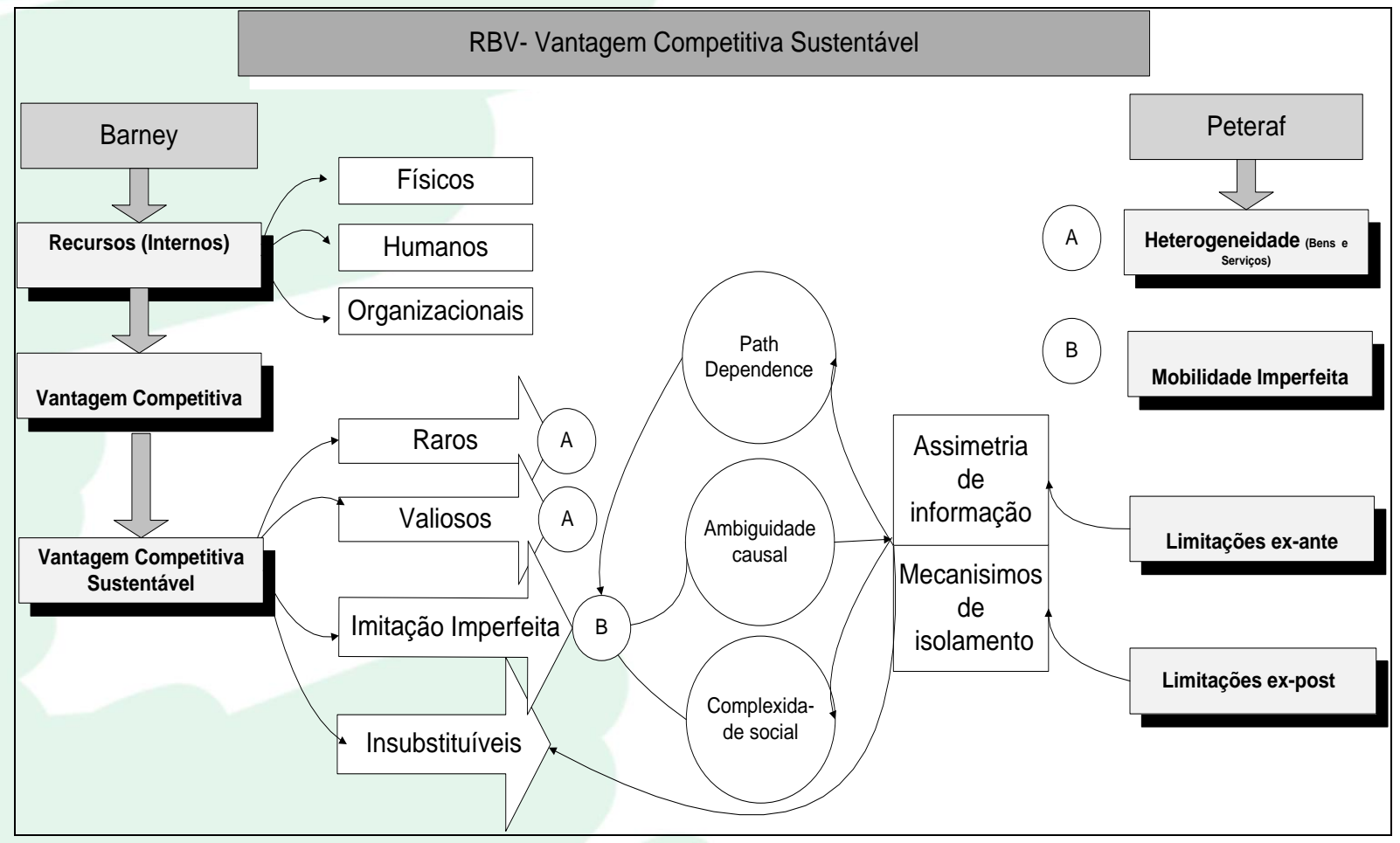

Fonte: Elaborado pelos autores.

A estrutura de capital, aliando finanças à estratégia, em ambientes turbulentos como no Brasil, pode ser vista como um recurso essencial.

\subsection{A ESTRUTURA DE CAPITAL COMO UM RECURSO ESSENCIAL}

A forma com que os gestores combinam as fontes de financiamento é uma decisão importante não só no contexto financeiro da firma, mas no estratégico também. A estrutura de capital trata da forma pela qual as firmas utilizam as fontes de recursos, próprios e de terceiros, para aplicar em ativos (assets) e atividades que as demandam. A escolha da melhor combinação das origens de recursos da estrutura de capital ainda é um tema recorrente em finanças. Estudos sobre os efeitos da alavancagem financeira nas decisões de melhor alocação de recursos nas organizações, historicamente, contribuíram para o avanço das discussões teóricas.

Durand (1952), em crítica a teoria econômica tradicional, propiciou proeminência aos problemas relacionados a investimentos e métodos de mensuração do custo de capital, próprio e de terceiros, incorporando seus efeitos na avaliação de resultados. Os juros e tributos foram considerados na proposição. Asseverou a necessidade de incorporar o fator risco, decorrente da incerteza, ao retorno dos investimentos, dado o endividamento assumido pela corporação. Esse

Revista Ibero-Americana de Estratégia - RIAE, São Paulo, v. 9, n. 1, p. 102-126, jan./abr. 2010. 
A Estrutura de Capital como Recurso e o Efeito no Desempenho das Firmas

estudo promoveu amplas discussões sobre o problema de mensuração do custo de financiamento da dívida e do patrimônio.

Modigliani e Miller (1958) trouxeram reconhecida contribuição à literatura de finanças, ao investigarem a influência das formas de financiamento no valor de mercado da firma. Abordaram dois critérios de tomada de decisão de financiamento: (a) a maximização de lucros, pressupondo que o ativo adquirido só tem valor se gerar lucros aos proprietários. O lucro incremental teria que exceder ao custo de capital; e (b) a maximização do valor de mercado da firma, onde um dado ativo passa a ser viável somente se gerar incremento ao valor da participação no capital dos proprietários. Desse modo, os rendimentos daí decorrentes teriam que superar aos juros do financiamento da dívida.

No trabalho de Modigliani e Miller (1958) duas afirmações centrais foram discutidas: a primeira, "o valor de mercado de qualquer firma é independente de sua estrutura de capital e é dado pela capitalização da expectativa da taxa de retorno apropriada para sua classe"; e a segunda, "o custo médio de capital de qualquer firma é completamente independente de sua estrutura de capital e é igual à taxa de capitalização de um fluxo completo de capital de sua classe". Concluindo que o valor da firma independe da estrutura de financiamento, seja por capitais próprios ou de terceiros (Durand, 1959; Abor, 2005; Omet, 2006). Como se vê, no mundo perfeito e completo de Modigliani e Miller não existe benefícios tributários, custos de transação, instituições fracas, custos da quebra ou assimetria de informações (Barton \& Gordan, 1987; Andersen, 2005).

Durand (1959), em adição às contribuições de Modigliani e Miller, afirmou que o valor da firma é função dos fluxos de caixa futuros descontados a uma dada taxa correspondente ao custo de oportunidade dos ativos. O valor da empresa é dependente da variação da taxa de juros, ceteris paribus. Durand (1959), em crítica ao trabalho de Modigliani e Miller (1958), destacou que não se podem desconsiderar distintivamente as características das corporações. As organizações em seu contexto possuem níveis diferenciados de vulnerabilidades. O fator risco é importante, pois não existe um mundo com $100 \%$ de baixo risco. O autor concluiu não ser tarefa fácil a formulação de custo de capital quando se tem mercado imperfeito.

Modigliani e Miller (1963) incorporaram os tributos como variáveis ao modelo, inferindo que o custo de capital gerado pela alavancagem traz, por seus efeitos, benefícios fiscais. Embora tenham incorporado os custos tributários, Durand (1952) ao comparar os métodos de avaliação de resultados - Net Operating Income (NOI) e o Net Income (NI) - já havia considerado esses efeitos na apuração do NI. Assim, reconheceram que a dedutibilidade fiscal dos custos da operação tem importância por minimizar o custo da alavancagem. Esta consideração produziu efeitos diferenciais

Revista Ibero-Americana de Estratégia - RIAE, São Paulo, v. 9, n. 1, p. 102-126, jan./abr. 2010. 
Silvio Parodi Camilo, Wlamir Gonçalves Xavier, Rodrigo Bandeira-de-Mello \& Rosilene Marcon

na escolha das fontes de financiamento. O incentivo a utilização de capitais de terceiros é limitado pelo risco de falência. As obrigações decorrentes das operações pressionam o fluxo de caixa da empresa, limitando o nível de endividamento. Este patamar, denominado de estrutura ótima de capital, maximiza a utilização do grau de liberdade do endividamento, conjugada ao aproveitamento das vantagens em termos tributários.

A partir dos seminais artigos de Modigliani e Miller (1958) e Durand (1959) houve reconhecido avanço no âmbito da teoria financeira. Miller (1977) explorou melhor os efeitos tributários do tomador e aplicador de recursos, onde reexaminou as vantagens tributárias da alavancagem, concluindo que há anulação de seus efeitos em termos macroeconômicos. Dessa forma, mesmo considerando os custos de falência e ganhos tributários, manteve a posição de origem, ou seja, de que há irrelevância ao valor da firma na escolha das modalidades de financiamento.

DeAngelo e Masulis (1980), como contraponto, discutiram o teorema de Miller identificando fragilidades em seu modelo, por desconsiderarem os efeitos tributários, custos de depreciação e créditos tributários decorrentes dos investimentos, tornando vulneráveis os argumentos de Modigliani e Miller. Ao contrário desses autores, concluíram que decisões de alavancagem produzem efeitos na valorização da firma. Assim, a melhor combinação da estrutura de capital é relevante para o valor da empresa.

Kane, Marcus e McDonald (1985) afirmaram que em mercado de capitais perfeito e completo o valor da firma independe da estrutura de capitais. Acrescentando que a tributação dos lucros e a existência de custos da falência são imperfeições do mercado. Justamente por isso que a base do modelo comprova que a alavancagem afeta o valor da firma. Primeiro pela possibilidade de risco de quebra, importando em custos e consequente redução no valor de mercado da firma. Segundo, porque há compensação dos custos da quebra através da proteção tributária gerada pela dedutibilidade dos juros incorridos. Partindo dessas considerações, ampliaram os modelos até então existentes, incorporando os benefícios da dívida, custos de falência e custos de transação associados à emissão de dívida, analisando os efeitos da alavancagem nas taxas de retorno das operações da firma.

Critérios para tomada de decisões sobre alavancagem foram amplamente estudados por Myers (1984). O autor identificou duas maneiras de pensar sobre a estrutura de capital: a) a static tradeoff theory em que a firma tem uma meta de endividamento e se move para este objetivo até o nível ótimo, incentivada pelos benefícios da dívida e limitada pelo risco de quebra; e b) a pecking order theory em que a firma segue uma ordem de preferência, primeiramente interna (lucros

Revista Ibero-Americana de Estratégia - RIAE, São Paulo, v. 9, n. 1, p. 102-126, jan./abr. 2010. 
A Estrutura de Capital como Recurso e o Efeito no Desempenho das Firmas

retidos) e após externa (emissão de dívida e emissão de ações). Essa hierarquia de preferência das fontes é explicada pela assimetria de informações, pressupondo que os gestores possuem mais conhecimento - informação superior - das oportunidades de seus ativos que os investidores externos (Myers \& Majiuf, 1984).

Nos estudos de Booth et al. (2001) concluíram que quanto maior o ROA das firmas, menor a proporção de dívidas, apontando a confirmação das hipóteses da pecking order theory. As firmas evitam o uso de capitais de terceiros por ser mais custoso. As firmas que fazem uso das fontes de longo prazo possuem maior tangibilidade dos ativos, influenciando as decisões de captação em razão dos colaterais disponíveis, com isso, as firmas estudadas não incrementaram dívida, mas fizeram mais uso de fontes de longo prazo em relação às de curto prazo. No Brasil, Silva e Valle (2008) desenvolveram um estudo comparativo entre a estrutura de endividamento das empresas brasileiras e americanas, período-base de 1999 a 2003. Concluíram que as empresas americanas utilizam maior proporção de dívidas de longo prazo em relação às nacionais e suas próprias dívidas. Apontando para tendência de elevação das dívidas de longo prazo, ao contrário das brasileiras que vêm aumentando a participação de fontes de curto prazo. Confirmaram os achados de Titman e Wessls (1988) que empresas pequenas possuem dívidas de curto prazo em preponderância, tornando-se mais sensíveis às turbulências do mercado. Brito, Corrar e Batistela (2007) analisaram os fatores determinantes da estrutura de capital nas maiores empresas brasileiras de capital aberto e fechado, compreendendo dados de 466 empresas nos anos de 1998 a 2002. Os resultados indicaram que o risco, tamanho, composição de ativos e crescimento são importantes fatores para determinação da estrutura de capital das firmas nacionais, ao contrário da rentabilidade e tipologia organizacional (capital aberto ou fechado).

Alternativas valiosas de investimentos geram perspectivas favoráveis de rendimentos. A escolha da fonte mais vantajosa, com base no privilégio informacional, produz efeitos aos investidores internos - acionistas antigos - e externos - acionistas potencias e novos - (Myers, 1984; Myers \& Majiuf, 1984; Abor, 2005). Empresas mais bem alavancadas têm amplo acesso a fontes de capitais, mais influência no mercado e menores restrições ao crédito, considerando que possuem menor assimetria de informações do mercado e desse sobre as firmas (Faulkender \& Petersen, 2005), geram, por sua vez, custos de transação mais favoráveis (Titman \& Wessels, 1988) em relação as demais competidoras. De acordo com o entendimento da RBV, determinados recursos e capacidades pertencentes às firmas são os que produzem vantagem competitiva e as tornam heterogêneas (Dierickx \& Cool, 1989), diferentemente da visão da OI.

Nesse sentido, o estudo propõe a seguinte hipótese central $(H 1)$ a ser testada:

Revista Ibero-Americana de Estratégia - RIAE, São Paulo, v. 9, n. 1, p. 102-126, jan./abr. 2010. 
Silvio Parodi Camilo, Wlamir Gonçalves Xavier, Rodrigo Bandeira-de-Mello \& Rosilene Marcon

H1: Decisões sobre estrutura de capital são fontes de vantagem competitiva em ambientes turbulentos, como o brasileiro.

\section{MÉTODO DE PESQUISA}

\subsection{DADOS E ESPECIFICAÇÕES DO MODELO}

A amostra foi composta por empresas listadas na Bovespa, cujos dados foram capturados da Economática ${ }^{\circledR}$, dos relatórios de administração e das demonstrações contábeis disponibilizadas nas Informações Anuais (IAN). O período de análise foi de seis anos (2002-2007), considerado razoável tendo por consideração outros estudos em finanças. Inicialmente foram classificadas 462 empresas pertencentes a 18 setores da economia, já deduzidos os da área financeira e de seguros, pois, em razão das características da estrutura de capital desses setores, os resultados seriam influenciados sobremodo.

Além disso, as seguintes empresas foram excluídas do modelo: concordatárias, em recuperação judicial ou extrajudicial, em processo falimentar, com patrimônio líquido negativo no ano, as que, nesse curso, foram incorporadas ou fundidas, as holdings e as controladoras, bem como as que constavam como inativas em 2007. Foi condição adotada pelos autores que as empresas deveriam possuir todas as variáveis utilizadas no modelo e que tivessem dados relativos a, no mínimo, três exercícios sociais. Por exemplo, algumas empresas não divulgaram dados de depreciação acumulada nos relatórios da Bovespa ou no site corporativo e, por consequência, não foram disponibilizados na Economática ${ }^{\circledR}$. Como esse dado é determinante para formar a métrica de longevidade dos ativos, uma das variáveis do modelo, as empresas que não divulgaram, nas fontes pesquisadas, foram excluídas da amostra.

\begin{tabular}{|c|l|}
\hline VARIÁVEL & \multicolumn{1}{|c|}{ DESCRIÇÃo } \\
\hline $\begin{array}{c}\text { Rentabilidade contábil dos ativos } \\
\text { líquidos (ROA_Ke) }\end{array}$ & $\begin{array}{l}\text { A rentabilidade dos ativos é determinada pela razão entre o Lucro Líquido } \\
\text { Operacional antes do Imposto de Renda, Contribuição Social sobre o Lucro e } \\
\text { Depreciações, e Despesas Financeiras (Ebitda), descontado o custo de } \\
\text { oportunidade (Ke), e o Ativo Operacional Líquido (ativo corrente mais } \\
\text { imobilizações escriturais). }\end{array}$ \\
\hline Retorno do acionista (ROE_Ke) & $\begin{array}{l}\text { Descreve a rentabilidade do acionista, descontado o custo de oportunidade (Ke), } \\
\text { determinado pela razão entre o Ebitda e o Patrimônio Líquido Escritural. }\end{array}$ \\
\hline
\end{tabular}

Revista Ibero-Americana de Estratégia - RIAE, São Paulo, v. 9, n. 1, p. 102-126, jan./abr. 2010. 
A Estrutura de Capital como Recurso e o Efeito no Desempenho das Firmas

\begin{tabular}{|c|l|}
\hline $\begin{array}{c}\text { Endividamento no Curto Prazo } \\
\text { (E_CP) }\end{array}$ & $\begin{array}{l}\text { Grau de comprometimento no curto prazo (CP), mensurado pela razão entre o } \\
\text { endividamento no CP e o Ativo Total. }\end{array}$ \\
\hline $\begin{array}{c}\text { Endividamento no Longo Prazo } \\
\text { (E_LP) }\end{array}$ & $\begin{array}{l}\text { Grau de comprometimento no longo prazo (LP), mensurado pela razão entre o } \\
\text { endividamento no LP e o Ativo Total. }\end{array}$ \\
\hline $\begin{array}{c}\text { Políticas de Fontes de Financiamento } \\
\text { (ALAV_PL) }\end{array}$ & $\begin{array}{l}\text { Ordem de preferência de obtenção de recursos. Medido através da razão entre o } \\
\text { endividamento total e o patrimônio Líquido. }\end{array}$ \\
\hline $\begin{array}{c}\text { Longevidade dos Ativos (LONGEV) } \\
\text { Tangibilidade dos Ativos }\end{array}$ & $\begin{array}{l}\text { Medida pela razão entre o Ativo Imobilizado líquido e o Ativo Imobilizado } \\
\text { (TAN_AO) }\end{array}$ \\
\hline $\begin{array}{l}\text { Líquido pedida razão entre o Ativo Imobilizado Líquido e o Ativo Operacional } \\
\text { Tamanho da empresa (TAM_RB) }\end{array}$ & \begin{tabular}{c} 
Logaritmo da Receita Bruta \\
\hline
\end{tabular} \\
\hline
\end{tabular}

Quadro 1 - Variáveis modeladas.

Fonte: Elaborado pelos autores.

No modelo foram consideradas as médias das variáveis dependentes e independentes por firma, ou seja, as métricas foram apuradas por exercício social e, posteriormente, apuradas as médias por firma. Após a apuração das métricas foram detectadas as observações discrepantes a partir de um gráfico de dispersão tendo como complemento a sugestão de Hair Jr. et al. (2009), foram considerados candidatos a outliers firmas com pelo menos 2,5 desvios-padrão. Ao final restaram 143 firmas que geraram 7.065 observações.

A variável dependente de desempenho foi mensurada considerando duas componentes: a dimensão contábil (ROA) e o retorno aos acionistas (ROE), ambos livres da taxa de risco (Ohlson, 1999), baseada na remuneração anual do CDI anual (Bandeira-de-Mello \& Marcon, 2004), conforme dados do Banco Central do Brasil: 2002 (19,11\%); 2003 (23,25\%); 2004 (16,17\%); 2005 $(19,08 \%)$; $2006(15,03 \%)$; e $2007(11,82 \%)$. As definições operacionais das demais variáveis modeladas estão no Quadro 1.

Seguindo a proposta de pesquisa, o modelo pretende examinar os efeitos da estrutura de capital na performance. Com esse propósito, foi elaborado um modelo geral, duas formulações daí derivadas. $\mathrm{O}$ constructo base entende que:

Performance $=\mathbf{f}$ (estrutura de capital, variáveis específicas da firma)

Revista Ibero-Americana de Estratégia - RIAE, São Paulo, v. 9, n. 1, p. 102-126, jan./abr. 2010. 
Silvio Parodi Camilo, Wlamir Gonçalves Xavier, Rodrigo Bandeira-de-Mello \& Rosilene Marcon

Dessa forma, na especificação do modelo geral, a performance é função da estrutura de capital e das variáveis específicas da firma. Dentre os atributos da estrutura de capital, no modelo, o endividamento de curto e longo prazo e a alavancagem (Procianoy \& Schnorrenberg, 2004). As variáveis específicas são as de controle, que visam capturar as características financeiras das firmas, determinadas como longevidade, tangibilidade e tamanho, amplamente utilizadas em finanças (Titman \& Wessls, 1988; Brito, Corrar, \& Batistela, 2007) cujos conceitos constam no Quadro 1.

O modelo estimado está descrito na Equação 1. As Equações 2 e 3 são derivadas da Equação 1 para cada indicador de performance utilizado. Assim, a performance da firma $i$, na indústria $k$, no ano $t$ é determinada por:

Performance $_{i, k, t}=\beta_{o}+\beta_{1} E_{-} L P+\beta_{2} E_{-} C P+\beta_{3} A L A V_{-}{ }^{3} P L+\sum_{\mathrm{J}=1} \beta_{4^{*}}$ Controles $+\square_{i, k, t}$

Sendo que,

Performance $_{i, k, t}=$ ROA_Ke

Performance $_{i, k, t}=\mathrm{ROE} \_\mathrm{Ke}$

$\mathrm{e}$

$\beta_{o}$ representa o intercepto e $\sum \beta_{4} *$ Controles $=L O N G E V, T A N \_A O$ e TAM_RB

Os setores da economia nacional, com base nos dados da Economática®; constantes da população são dados por variáveis dicotômicas, dummy_setores: Agroindústria e Pesca; Alimentos e Bebidas; Comércio; Construção; Eletroeletrônico; Energia Elétrica; Máquinas Industriais; Mineração; Minerais Não Metálicos; Papel e Celulose; Petróleo e Gás; Química; Siderurgia e Metalurgia; Software e Dados; Telecomunicações; Têxtil; Transportes Serviços; e Veículos e Peças. Dessa forma, a firma pertencente a determinado setor assume 1 (um) e, do contrário, assume $\mathbf{0}$ (zero).

Por fim, o $\square$ representa o termo erro; expressa os fatores inobserváveis pelo modelo que afetam a variável dependente. Entretanto, observa-se que pode conter erros de medida nas variáveis observadas, dependentes e independentes (Wooldrige, 2007).

Revista Ibero-Americana de Estratégia - RIAE, São Paulo, v. 9, n. 1, p. 102-126, jan./abr. 2010. 
A Estrutura de Capital como Recurso e o Efeito no Desempenho das Firmas

\section{DISCUSSÃO E RESULTADOS}

A Tabela 1, a seguir, apresenta os níveis médios das variáveis e as respectivas correlações no período. A matriz descritiva confirma que um construto de performance composto de ambos ROA_ke e ROE_ke não seria adequado, dada à sua alta colinearidade. Enquanto, em relação ao ROE_ke, em média, houve remuneração acima do custo de oportunidade, por conseguinte, geração de valor aos acionistas. Observou-se grande dispersão dos valores dos retornos da firma, indicando a ocorrência de retornos anormais entre firmas e setores.

Tabela 1 - Matriz descritiva e de correlação das variáveis.

\begin{tabular}{|c|c|c|c|c|c|c|c|c|c|c|}
\hline \multirow{2}{*}{ Variáveis } & \multicolumn{2}{|c|}{ Vars. Descritivas } & \multicolumn{2}{|c|}{ Vars. Dep. } & \multicolumn{3}{|c|}{ Estrutura de Capital } & \multicolumn{3}{|c|}{ Vars. de Controle } \\
\hline & Média & Desv. Pad & ROA_ke & ROE_Ke & E_CP & E_LP & ALAV_PL & LONGEV & TAN_AO & TAM_RB \\
\hline ROA_ke & $-5,6 \%$ & $14,9 \%$ & 1,000 & & & & & & & \\
\hline ROE_Ke & $14,7 \%$ & $34,4 \%$ & $0,503^{*}$ & 1,000 & & & & & & \\
\hline E_CP & $31,0 \%$ & $12,9 \%$ & $-0,137$ & 0,113 & 1,000 & & & & & \\
\hline E_LP & $25,8 \%$ & $15,8 \%$ & $-0,017$ & $0,394 *$ & $-0,264^{*}$ & 1,000 & & & & \\
\hline ALAV_PL & 2,430 & 2,900 & $-0,067$ & $0,641^{*}$ & $0,293^{*}$ & $0,526^{*}$ & 1,000 & & & \\
\hline LONGEV & $52,6 \%$ & $17,8 \%$ & $0,160^{\#}$ & 0,122 & $-0,252^{*}$ & $0,344 *$ & 0,125 & 1,000 & & \\
\hline TAN_AO & $37,6 \%$ & $20,3 \%$ & $-0,027$ & $-0,001$ & $-0,342^{*}$ & $0,413^{*}$ & 0,060 & $0,426^{*}$ & 1,000 & \\
\hline TAM_RB & 5,891 & 0,731 & $0,434 *$ & $0,282^{*}$ & $-0,045$ & 0,125 & $-0,081$ & 0,127 & 0,114 & 1,000 \\
\hline
\end{tabular}

Fonte: Elaborado pelos autores.

Quanto à estrutura de capitais, a Tabela 1 aponta que o endividamento de curto prazo é preponderante em relação ao de longo prazo, confirmando os achados de Brito, Corrar e Batistela (2007). Destaque-se que os dados da amostra apresentam estabilidade na estrutura de capitais das firmas, confirmado pelos desvios. A alavancagem sobre o Patrimônio Líquido aponta que há preponderância na participação dos capitais de terceiros em relação aos capitais próprios, apresentando desvio-padrão moderado.

Quanto às variáveis de controle, os dados anuais da longevidade dos ativos, constantes da base analítica, indicam que, ao longo do período, as firmas mantiveram investimentos de reposição em ativos imobilizados, na mesma medida do reconhecimento da perda de potencialidade operacional (taxas de depreciação de acordo com as normativas tributárias). O indicador aponta que, em média, a metade dos valores dos bens imobilizados das firmas encontra-se depreciada. A Longevidade e a Tangibilidade, variáveis de controle que apresentaram distribuição normal, se mostraram pouco dispersas e desvio padrão moderado. A variável Tamanho não apresentou distribuição normal, mesmo após ser submetida às transformações padrão. Optou-se pela 
Silvio Parodi Camilo, Wlamir Gonçalves Xavier, Rodrigo Bandeira-de-Mello \& Rosilene Marcon

logarítmica (Rodrigues \& Paulo, 2007; Hair Jr. et al., 2009), que revelou pouca dispersão dessa variável, mensurada pela receita bruta entre as médias das empresas.

Em relação à estrutura de capital, o ROA_ke apresentou baixa correlação negativa de forma não significativa. Só em relação à longevidade e ao tamanho a correlação foi significativa, guardando relação moderada com essa variável. O ROE_ke está melhor relacionado ao Endividamento de Longo Prazo e a Alavancagem, com correlação moderada e substancial, respectivamente, denotando que firmas mais alavancadas proporcionam melhor remuneração aos acionistas. Essa variável se relacionou com o TAM_RB de forma positiva, porém com baixa correlação. Os dados também revelam que firmas maiores geram mais rentabilidade dos ativos do que aos acionistas.

Na Tabela 2, apresentam-se os parâmetros da regressão linear que modelam a performance (ROA_ke e ROE_ke), conforme a equação 2 .

O modelo explica $21,7 \%$ das variações que ocorrem na ROA_ke por meio de variações nas variáveis preditoras. No conjunto as variáveis influenciam a variável critério, pois a regressão foi estatisticamente significativa, entretanto, demonstra-se que o grau de explicação do modelo é reduzido, sendo mais influenciado pela variabilidade das métricas TAM_RB e E_CP. As alterações ocorridas na alavancagem, longevidade e tamanho são ajustadas pelo endividamento, de curto e longo prazo, e a tangibilidade.

Tabela 2 - Coeficientes do modelo de regressão ROA_ke.

\begin{tabular}{|c|c|c|c|c|c|c|c|}
\hline \multirow[t]{2}{*}{ Modelo } & \multicolumn{2}{|c|}{$\begin{array}{c}\text { Coeficientes não } \\
\text { padronizados }\end{array}$} & \multirow{2}{*}{\begin{tabular}{|c}
$\begin{array}{l}\text { Coeficiente } \\
\text { padronizado }\end{array}$ \\
Beta
\end{tabular}} & \multirow[b]{2}{*}{$\mathrm{t}$} & \multirow[b]{2}{*}{ Sig. } & \multicolumn{2}{|c|}{$\begin{array}{l}\text { Estatística de } \\
\text { colinearidade }\end{array}$} \\
\hline & $\mathrm{B}$ & Erro-padrão & & & & Tolerância & VIF \\
\hline 1 (Constante) & $-0,523$ & 0,100 & & $-5,223$ & 0,000 & & \\
\hline E_CP & $-0,242$ & 0,108 & $-0,210$ & $-2,243$ & 0,027 & 0,631 & 1,584 \\
\hline E_LP & $-0,173$ & 0,103 & $-0,184$ & $-1,670$ & 0,097 & 0,456 & 2,194 \\
\hline ALAV_PL & 0,006 & 0,005 & 0,116 & 1,101 & 0,273 & 0,498 & 2,007 \\
\hline LONGEV & 0,136 & 0,071 & 0,163 & 1,922 & 0,057 & 0,769 & 1,300 \\
\hline TAN_AO & $-0,111$ & 0,065 & $-0,151$ & $-1,694$ & 0,092 & 0,696 & 1,438 \\
\hline TAM_RB & 0,092 & 0,016 & 0,453 & 5,908 & 0,000 & 0,937 & 1,067 \\
\hline $\mathbf{R 2}$ & R2 Ajust & DW & $\mathbf{F}$ & & & & \\
\hline 0,251 & 0,217 & 1,996 & 7,578 & & & & \\
\hline
\end{tabular}

Fonte: Elaborado pelos autores.

Revista Ibero-Americana de Estratégia - RIAE, São Paulo, v. 9, n. 1, p. 102-126, jan./abr. 2010. 
O modelo, em geral, não revelou alta colinearidade entre as variáveis preditoras. . Importante destacar que uma possível multicolineridade entre as variáveis preditoras foi descartada, já que o modelo apresentou valores de VIF inferiores a 2,2 (Gujarati, 2006).

A Tabela 3, a seguir, apresenta os coeficientes do modelo utilizando como variável dependente ROE_ke (equação 3). Esse modelo de regressão apresenta coeficiente de determinação ajustado de $52,1 \%$. Com isso, vê-se que o conjunto de variáveis preditoras consegue explicar parte representativa da variável critério. Dentre as variáveis da estrutura de capital somente a ALAV_PL é significativa. A variável de controle Tamanho se mostrou significativa, de modo a indicar que é influente na geração da Rentabilidade Sobre os Capitais Próprios. As demais variáveis não foram estatisticamente significativas.

O primeiro modelo, que buscou avaliar a performance a partir do retorno sobre ativos operacionais (ROA_ke) não apresentou poder de explicação aceitável. Assim, a capacidade gerenciamento da firma em relação à captação e aplicação de capitais de terceiros não se mostrou determinante. Os dados sugerem que quanto menor a participação das dívidas de curto prazo maior a contribuição para a elevação da rentabilidade operacional. Em geral, infere-se que, com base nos dados utilizados, não se pode afirmar que a estrutura de capital é fonte de vantagem competitiva, não sendo conclusiva, portanto, a hipótese H1 quando aplicado o construto ROA_ke descrito na equação (2).

Considerando o constructo ROE_ke, demonstra-se que o poder de explicação das variáveis preditoras é significativo. A alavancagem se mostrou significativa ensejando que, em relação à rentabilidade dos capitais próprios, é determinante. Depreende-se que empresas mais alavancadas têm menores limitações ao acesso de capitais, obtendo mais vantagem competitiva. Fazer uso: da alavancagem como recurso aliado ao efeito tamanho é importante fonte de vantagem competitiva. Concluindo-se que a hipótese $H 1$ em relação ao constructo ROE_ke pode ser confirmada.

Revista Ibero-Americana de Estratégia - RIAE, São Paulo, v. 9, n. 1, p. 102-126, jan./abr. 2010. 
Silvio Parodi Camilo, Wlamir Gonçalves Xavier, Rodrigo Bandeira-de-Mello \& Rosilene Marcon

Tabela 3 - Coeficientes do modelo de regressão ROE_ke .

\begin{tabular}{|c|c|c|c|c|c|c|c|}
\hline \multirow[t]{2}{*}{ Modelo } & \multicolumn{2}{|c|}{$\begin{array}{c}\text { Coeficientes não } \\
\text { padronizados }\end{array}$} & \multirow{2}{*}{\begin{tabular}{|c|}
$\begin{array}{l}\text { Coeficiente } \\
\text { padronizado }\end{array}$ \\
Beta \\
\end{tabular}} & \multirow[b]{2}{*}{$\mathrm{t}$} & \multirow[b]{2}{*}{ Sig. } & \multicolumn{2}{|c|}{$\begin{array}{l}\text { Estatística de } \\
\text { colinearidade }\end{array}$} \\
\hline & $\mathrm{B}$ & Erro-padrão & & & & Tolerância & VIF \\
\hline 1 (Constante) & $-0,850$ & 0,182 & & $-4,685$ & 0,000 & & \\
\hline E_CP & $-0,333$ & 0,196 & $-0,124$ & $-1,702$ & 0,091 & 0,631 & 1,584 \\
\hline E_LP & $-0,025$ & 0,187 & $-0,012$ & $-0,136$ & 0,892 & 0,456 & 2,194 \\
\hline ALAV_PL & 0,085 & 0,010 & 0,717 & 8,712 & 0,000 & 0,498 & 2,007 \\
\hline LONGEV & 0,030 & 0,128 & 0,016 & 0,235 & 0,815 & 0,769 & 1,300 \\
\hline TAN_AO & $-0,218$ & 0,118 & $-0,128$ & $-1,842$ & 0,068 & 0,696 & 1,438 \\
\hline TAM_RB & 0,164 & 0,028 & 0,349 & 5,809 & 0,000 & 0,937 & 1,067 \\
\hline $\mathbf{R 2}$ & R2 Ajust & DW & $\mathbf{F}$ & & & & \\
\hline 0,541 & 0,521 & 1,90 & 26,723 & & & & \\
\hline
\end{tabular}

Fonte: Elaborado pelos autores.

Foi observado que os efeitos do endividamento tanto de curto quanto de longo prazo na performance são plenamente explicados somente pela alavancagem. Utilizando um modelo de regressão pela técnica Stepwise Forward, foi constatado que o poder de explicação de um modelo composto somente pela alavancagem e Tamanho é semelhante àquele obtido a partir do construto da equação (2), ou seja, $\mathrm{R}^{2}$ ajustado de $52 \%$.

Nesse sentido, as firmas alavancadas possuem maiores acessos a fontes de capitais, desenvolvem maior poder de influência no mercado, e o estreitamento dessas relações possibilita redução de restrições e minimização de assimetria informacional (Faulkender \& Petersen, 2005). O gerenciamento equilibrado no uso dos recursos de modo a atingir o "nível ótimo de alavancagem" (Myers, 1984) é uma decisão importante em finanças. O melhor uso dessa combinação pode gerar vantagens de natureza tributária, (DeAngelo \& Masulis, 1980), importando em vantagem competitiva distintiva (Dierickx \& Cool, 1989), sendo um recurso e capacidade essencial à performance.

Os dados da amostra indicam que as firmas fazem uso desses recursos seguindo a teoria tradeoff. Os efeitos das decisões de gerenciamento da dívida, benefícios fiscais e as restrições, como a quebra, colaterais, e o risco, são capacidades importantes que a firma, ao desenvolver, torna-se singular para a obtenção de vantagem competitiva.

Revista Ibero-Americana de Estratégia - RIAE, São Paulo, v. 9, n. 1, p. 102-126, jan./abr. 2010. 
A Estrutura de Capital como Recurso e o Efeito no Desempenho das Firmas

\section{CONSIDERAÇÕES FINAIS}

Neste trabalho, por meio da união dos campos do conhecimento Finanças e Estratégia, pretendeu-se explorar a forma de combinação das fontes de capital e ver da sua essencialidade. Os constructos foram formulados considerando as Rentabilidades em dois níveis, (a) sobre os ativos operacionais líquidos e (b) sobre o patrimônio escritural, ambas livres do custo de oportunidade (ke).

Somente o modelo ROE_ke apresentou bom grau de explicação do fenômeno $\left(\mathrm{R}^{2}\right)$. Os achados indicaram que firmas que melhor fazem uso da alavancagem obtêm melhor performance operacional (Ebitda) e, por sua vez, remuneração do capital aos acionistas. Dentre as variáveis explanatórias de estrutura de capital, o Endividamento de Curto Prazo e de Longo Prazo não ofereceram contribuição para explicar a variabilidade do ROE_ke. Mas não se pode concluir que a escolha de um ou de outro seja indiferente, visto que os efeitos produzidos promovem impactos distintivos no resultado da firma, como, por exemplo, os custos financeiros e os benefícios da dívida estariam refletidos no lucro contábil e não estão impactos no Ebitda.

Em relação à estrutura de capital, observe-se que o E_LP, ao se mostrar mais bem relacionado com a ALAV_PL, aponta que a informação que aquela variável consegue explicar, de certa maneira, já está representada nessa, ou seja, informa pouco além do que a Alavancagem já informou. Essa relação, também, demonstra que firmas mais alavancadas fazem uso em maior escala de fontes de longo prazo. Assim, sob a ótica da RBV, fazer uso desse recurso contribui para a obtenção e sustentação de vantagem competitiva.

Firmas que fazem uso de recursos de longo prazo invertem recursos em ativos fixos e possuem maior tangibilidade, denotando que a renovação dos ativos imobilizados operacionais é dependente das fontes de longo prazo. Assim, os dados analíticos indicaram que as firmas alocam recursos à operação e seguem determinada estabilidade de acordo com as características setoriais, ou seja, empresas que necessitam de ativos imobilizados operacionais, como instalações, parque fabril, veículos de carga, maquinário, entre outros, possuem maior longevidade e, por sua vez, tangibilidade.

Por tudo considerado, esse estudo conclui que a hipótese geral pode ser confirmada somente em relação ao constructo ROE_ke,. As evidências revelaram que decisões sobre alavancagem se mostram importantes na geração de vantagem competitiva. As firmas que melhor fazem uso desse recurso, ou seja, mais bem gerenciam o uso de fontes de capitais de terceiros em relação aos capitais próprios, obtêm melhores resultados. As firmas da amostra utilizaram a teoria tradeoff nas

Revista Ibero-Americana de Estratégia - RIAE, São Paulo, v. 9, n. 1, p. 102-126, jan./abr. 2010. 
Silvio Parodi Camilo, Wlamir Gonçalves Xavier, Rodrigo Bandeira-de-Mello \& Rosilene Marcon

decisões que importaram em escolha de fontes de capitais. De fato, essa teoria demonstra que o seu uso há limites em razão do risco de falência. Firmas que equacionam fatores como benefícios versus risco, atingindo o nível ótimo de alavancagem com vantagem competitiva sustentável, pode-se deduzir que possuem capacidade de decisão idiossincrática em finanças e estratégia.

Este trabalho tem reconhecidas limitações. A primeira é quanto o tamanho da amostra, pois, os critérios firmados no método a restringiram sobremodo, por conseguinte, a normalidade dos dados foi afetada. Outras formas de amenizar os efeitos da normalidade poderiam ter sido testadas. $\mathrm{O}$ uso do ROE como indicador deve ser observado com reservas devido à correlação observada entre as variáveis. O período de 6 anos da amostra é outra limitação a ser considerada. Outro aspecto, o Ebitda ao ser considerado, tanto para avaliar a remuneração dos ativos operacionais quanto os capitais, não compreendeu os efeitos financeiros originados pelas decisões de financiamentos dos capitais, ou seja, o modelo pode ter explicado a variabilidade do ROE_ke pela Alavancagem, porém, ao desconsiderar os efeitos da depreciação, custos financeiros e benefícios fiscais, não se poderia afirmar com certeza a essencialidade dessa relação. A colinearidade potencialmente gerada ao considerar os construtos alavancagem e retorno sobre o capital próprio, tendo o mesmo denominador, pode ser mitigada com outro construto para a alavancagem, como por exemplo, a razão entre passivos onerosos e ativos totais. Reconhece-se que as restrições adotadas pelos autores prejudicam generalizações sobre as firmas listadas na Bovespa.

Sugestão para novos estudos e/ou desdobramento desta pesquisa: investigar setores específicos agregando ao modelo suas características; aumentar o horizonte de tempo de análise com o objetivo de eliminar efeitos cíclicos. A replicação deste modelo a estudos setoriais, incluindo novas variáveis dependentes, pode aumentar o grau de explicação e ajuste do modelo e identificar características setoriais e das firmas sob a ótica da RBV. Outro aspecto é referente à ausência da variável representativa dos ativos intangíveis no modelo, conforme sugerido por Myers (1977), que poderia ampliar os achados e contribuir para confirmar ou refutar a hipótese geral sob esse aspecto.

Revista Ibero-Americana de Estratégia - RIAE, São Paulo, v. 9, n. 1, p. 102-126, jan./abr. 2010. 
A Estrutura de Capital como Recurso e o Efeito no Desempenho das Firmas

\section{REFERÊNCIAS}

Abor, J. (2005). The effect of capital structure on profitability: an empirical analysis of listed firms in Ghana. The Journal of Risk Finance, 6(5). http://dx.doi.org/10.1108/15265940510633505

Acedo, F., Barroso, C., \& Galan, J. L. (2006). The resource-based theory: dissemination and main trends. Strategic Management Journal, 27(7). http://dx.doi.org/10.1002/smj.532

Andersen, T. (2005). Capital structure, environmental, dynamism, innovation strategy, and strategic risk management. SMG Working Paper, 10.

Bandeira-de-Mello, R., \& Marcon, R. (2004). Avaliação da eficácia das estratégias de posicionamento e do nível de atratividade setorial, do ponto de vista do acionista. $R A C, 8(2)$.

Barney, J. (1991). Firm resources and sustained competitive advantage. Journal of Management, 7(1), 99-120. http://dx.doi.org/10.1177/014920639101700108

Barney, J. (2001). Resource-based theories of competitive advantage a ten-year retrospective on the resource-based view. Journal of Management, 27, 643-650. http://dx.doi.org/10.1177/014920630102700602

Booth, L., A. V., Demirguc-Kunt, A., \& Maksimovic, V. (2001). Capital structures in developing countries. The Journal of Finance, LVI.

Brito, G. A. S., Corrar, L. J., \& Batistela, F. D. (2007) Fatores determinantes da estrutura de capital das maiores empresas que atuam no Brasil. Revista Contabilidade e Finanças, 43,9-19.

Collins, D., \& Montgomery, C. (2000). Competindo com base em recursos: estratégia na década de 1990. In Harvard Business Review. Estratégia corporativa. Rio de Janeiro: Campus.

Conner, K. (1991). A historical comparison of resource-based theory and five schools of thought within industrial organization economics: do we have a new theory of the firm? Journal of Management, 17(121).

Deangelo, H., \& Masulis, R. (1980). Optimal capital structure under corporate and personal taxation. Journal of Financial Economics, 8(1). http://dx.doi.org/10.1016/0304-405X(80)90019-7

Deephouse, D. (2000). Media reputation as a strategic resource: an integration of mass communication and resource-based theories, Journal of Management, 26(6), 1091- 1112. http://dx.doi.org/10.1177/014920630002600602

Revista Ibero-Americana de Estratégia - RIAE, São Paulo, v. 9, n. 1, p. 102-126, jan./abr. 2010. 
Silvio Parodi Camilo, Wlamir Gonçalves Xavier, Rodrigo Bandeira-de-Mello \& Rosilene Marcon

Dierickx, I., \& Cool, K. (1989). Asset stock accumulation and sustainability of competitive advantage. Management Science, 33(12).

Durand, D. (1952). Cost of debt and equity funds for business: trends and problems of measurement. In Conference on Research on Business Finance. New York: National Bureau of Economic Research.

Durand, D. (1959). The Cost of Capital, Corporation Finance, and the Theory of Investment: Comment. The American Economic Review, 639-655.

Faulkender, M., \& Petersen, M. (2006). Does the source of capital affect capital structure? The Review of Financial Studies, 19(1).

Ferguson, T. D., Deephose, D. L., \& Ferguson, W. L. (2000). Do strategic groups differ in reputation? Strategic Management Journal, 21(12).

http://dx.doi.org/10.1002/1097-0266(200012)21:12<1195::AID-SMJ138>3.0.CO;2-R http://dx.doi.org/10.1002/1097-0266(200012)21:12<1195::AID-SMJ138>3.3.CO;2-I

Gujarati, D. (2006). Econometria básica. Rio de Janeiro: Elsevier.

Hair Jr., Black, W. C., Babin, B. J., Anderson, R. E., \& Tatham, R. L. (2009). Análise multivariada de dados (6a ed.) Porto Alegre: Artmed.

Kahn, K. (1998). Characterizing interfunctional coordination and its implications for marketing orientation and performance. Proceedings of American Marketing Association Winter Conference, 321-327.

Kane, A., Marcus, A. J., \& McDonald, R. L. (1985). Debt policy and the rate of return premium to leverage. Journal of Financial and Quantitative Analysis, 20(4), 479-499.

http://dx.doi.org/10.2307/2330763

Kor, Y., Mahoney, J., \& Penrose , E. (1959). Contributions to the resource-based view of strategic management. Journal of Management Studies. 41(1), 183-191. http://dx.doi.org/10.1111/j.1467-6486.2004.00427.x

Kupfer, D., \& Hasenclever, L. (Orgs.). (2002). Fundamentos teóricos e práticas no Brasil. In Economia Industrial. Introdução e Cap. 2. Rio de Janeiro: Campus.

McWilliams, A., \& Smart, D. (1995). The resource-based view of the firm does it far enough in shedding the assumptions of the S-C-P paradigm? Journal of Management Inquiry, 4, 309-316. http://dx.doi.org/10.1177/105649269500400402

Miller, M. (1977). Debt and taxes. Journal of Finance, 32(2). http://dx.doi.org/10.2307/2326758

Revista Ibero-Americana de Estratégia - RIAE, São Paulo, v. 9, n. 1, p. 102-126, jan./abr. 2010. 
A Estrutura de Capital como Recurso e o Efeito no Desempenho das Firmas

Modigliani, F., \& Miller, M. (1958). The cost of capital, corporation finance, and the theory of investment. American Economic Review, 48(3).

Modigliani, F., \& Miller, M. (1963). Corporate income taxes and the cost of capital: a correction. American Economic Review, 53(3).

Myers, S. (1977). Determinants of corporate borrowing. Journal of Financial Economics, 5(2), 147-175. http://dx.doi.org/10.1016/0304-405X(77)90015-0

Myers, S. (1984). The capital structure puzzle. Journal of Finance, 39(3). http://dx.doi.org/10.2307/2327916

Myers, S., \& Majluf, N. (1984). Corporate financing and investment decisions when firms have information that investors do not have. Journal of Financial Economics, 13.

Nelson, R. (1991). Why do firms differ, and How Does It Matter? Strategic Management Journal, $12,61-74$.

http://dx.doi.org/10.1002/smj.4250121006

Ohlson, J. (1999). Earnings, book values, and dividends in a stewardship setting with moral hazard. Contemporary Accounting Research, 16(3). http://dx.doi.org/10.1111/j.1911-3846.1999.tb00594.x

Omert, G. (2006). Ownership Structure and Capital Structure; evidence from the Jordanian capital market (1995-2003). Corporate Ownership \& Control, 3(4), 99-107.

Peng, M. (2008). Estratégia Global. São Paulo:Thompson.

Penrose, E. (1959). The theory of growth of the firm. London: Basil Blackwell.

Peteraf, M. (1993). The cornerstones of competitive advantage: a resource-based view. Strategic Management Journal, 14, 179-191. http://dx.doi.org/10.1002/smj.4250140303

Porter, M. (1986). Estratégia Competitiva: técnicas para análise de indústrias e da concorrência (cap.1, 2 e 7). Rio de Janeiro: Campus.

Procianoy, J. L., \& Schnorrenberg, A. A influência da estrutura de controle nas decisões de estrutura de capital das companhias brasileiras. Revista Brasileira de Economia, 58 (1), 121-146.

Reinhardt, F. (1998). Environmental product differentiation: implications for corporate strategy. California Management Review, 40, 43-73.

Revista Ibero-Americana de Estratégia - RIAE, São Paulo, v. 9, n. 1, p. 102-126, jan./abr. 2010. 
Silvio Parodi Camilo, Wlamir Gonçalves Xavier, Rodrigo Bandeira-de-Mello \& Rosilene Marcon

Rodrigues, A., \& Paulo, E. (2007). Análise multivariada: para os cursos de administração, ciências contábeis e economia. In FIPECAFI. Corrar, L. J., Paulo, E, \& Dias Filho, J. M. (Coords.). Introdução à Análise Multivariada. São Paulo: Atlas.

Silva, A., \& Valle, M. (2008). Análise da Estrutura de endividamento: um estudo comparativo entre empresas brasileiras e americanas. Revista de Administração Contemporânea, 12(1), 201-229.

Titman, S., \& Wessls, R. (1988). The determinants of capital structure choice. Journal of Finance, 43(1).

http://dx.doi.org/10.2307/2328319

Vasconcelos, F., \& Cyrino, A. (2000). Vantagem competitiva: os modelos teóricos atuais e a convergência entre estratégia e teoria organizacional. Revista de Administração de Empresas, 40(4).

Wernerfeld, B. (1984). A resource-based view of the firm. Strategic Management Journal, 5, 171180. http://dx.doi.org/10.1002/smj.4250050207

Wooldridge, J. M. (2007). Introdução à econometria: uma abordagem moderna (R. C. Souza \& J. A. Ferreira, trads.). São Paulo: Thomson Learning.

\section{Recebido: 04/01/2010}

Aprovado: 25/03/2010

Revista Ibero-Americana de Estratégia - RIAE, São Paulo, v. 9, n. 1, p. 102-126, jan./abr. 2010. 